\section{Cureus}

Received 03/05/2019

Review began 04/05/2019

Review ended 05/04/2019

Published 05/07/2019

\section{(C) Copyright 2019}

Farooq et al. This is an open access article distributed under the terms of the Creative Commons Attribution License CC-BY 3.0., which permits unrestricted use, distribution, and reproduction in any medium, provided the original author and source are credited.

\title{
Streptococcus gordonii Empyema: A Rare Presentation of Streptococcus gordonii Infection
}

\author{
Hafsa Farooq ${ }^{1}$, Tayyaba Mohammad ${ }^{2}$, Amna Farooq ${ }^{3}$, Qasim Mohammad ${ }^{4}$
}

1. Internal Medicine, Waterbury Hospital, Waterbury, USA 2. Internal Medicine, Rutgers New Jersey Medical School, Jersey City, USA 3. Miscellaneous, Shaikh Khalifa Bin Zayed Al-Nahyan Medical and Dental College, Lahore, PAK 4. Internal Medicine, Windsor University School of Medicine, Boonton, USA

$\square$ Corresponding author: Hafsa Farooq, hafsafrq88@gmail.com

Disclosures can be found in Additional Information at the end of the article

\section{Abstract}

Empyema is often caused by Streptococcus pneumoniae, Staphylococcus aureus, and a variety of gram-negative organisms as well as anaerobes. Streptococcus gordonii (S. gordonii) is among some of the initial colonizers of the periodontal environment that is recognized to cause bacterial endocarditis. However, there are only a few case reports of S. gordonii causing empyema in the literature. We report the case of a 75 -year-old male who presented with coughing up blood-tinged sputum. Physical examination revealed decreased breath sounds in the right lung base. Chest X-ray demonstrated a lower, right-sided, loculated pleural effusion. He underwent ultrasound-guided chest tube placement. The pleural fluid culture grew S. gordonii. He was started on ampicillin/ sulbactam. The follow-up computed tomography (CT) scan showed no significant improvement. Given his inability to improve with antibiotics and chest tube drainage, he was referred to an advanced care center for decortication of lung tissue.

Categories: Internal Medicine, Infectious Disease, Pulmonology

Keywords: strep gordonii, empyema, streptococcus gordonii

\section{Introduction}

For many years, Streptococcus (S.) pneumoniae, S. aureus, S. pyogenes, and some anaerobes have been studied to be the leading pathogens associated with empyema. Viridans streptococci, including Streptococcus gordonii, are anaerobic, gram-positive organisms that normally inhabit the oral tract and are often associated with dental plaque formation. This bacterium has been established as one of the main causative organisms in the development of subacute bacterial endocarditis (SBE) [1]. However, the literature on the implications of these organisms in other infections, such as empyema, is limited.

\section{Case Presentation}

A 75-year-old male with a history of tobacco abuse and depression was admitted to a community hospital due to three weeks of fatigue and two days of coughing up blood-tinged sputum. The physical examination was significant for decreased breath sounds on the right lung base and normal oral cavity with no cervical lymphadenopathy. The initial laboratory evaluation was normal and did not reveal leukocytosis. Blood cultures were negative. Human immunodeficiency virus (HIV) test was non-reactive. Chest radiograph revealed a large, lower, right-sided loculated effusion (Figure 1). He underwent ultrasound (US)-guided chest tube placement, which yielded $200 \mathrm{ml}$ of exudative fluid with $34,300 / \mathrm{mm}^{3}$ nucleated white blood 


\section{Cureus}

cells (1372/mm $\mathrm{mm}^{3}$ granulocytes). Pleural fluid was sent for laboratory analysis. He was started on intravenous (IV) ampicillin/sulbactam. Pleural fluid culture yielded a rare species, S. gordonii. During his stay at the hospital, he was noticed to have mild dysphagia with regular diet. Aspiration was thought to be the reason for his infection. Repeat chest X-ray showed a worsening of empyema. tPA was administered in the chest tube, which yielded $550 \mathrm{cc}$ of the exudative fluid. Follow-up CT chest revealed loculated effusions. Due to failed chest tube drainage with tPA and no improvement in the loculated effusions with antibiotics, he was transferred to a more advanced center for video-assisted thoracoscopic (VATS) decortication.

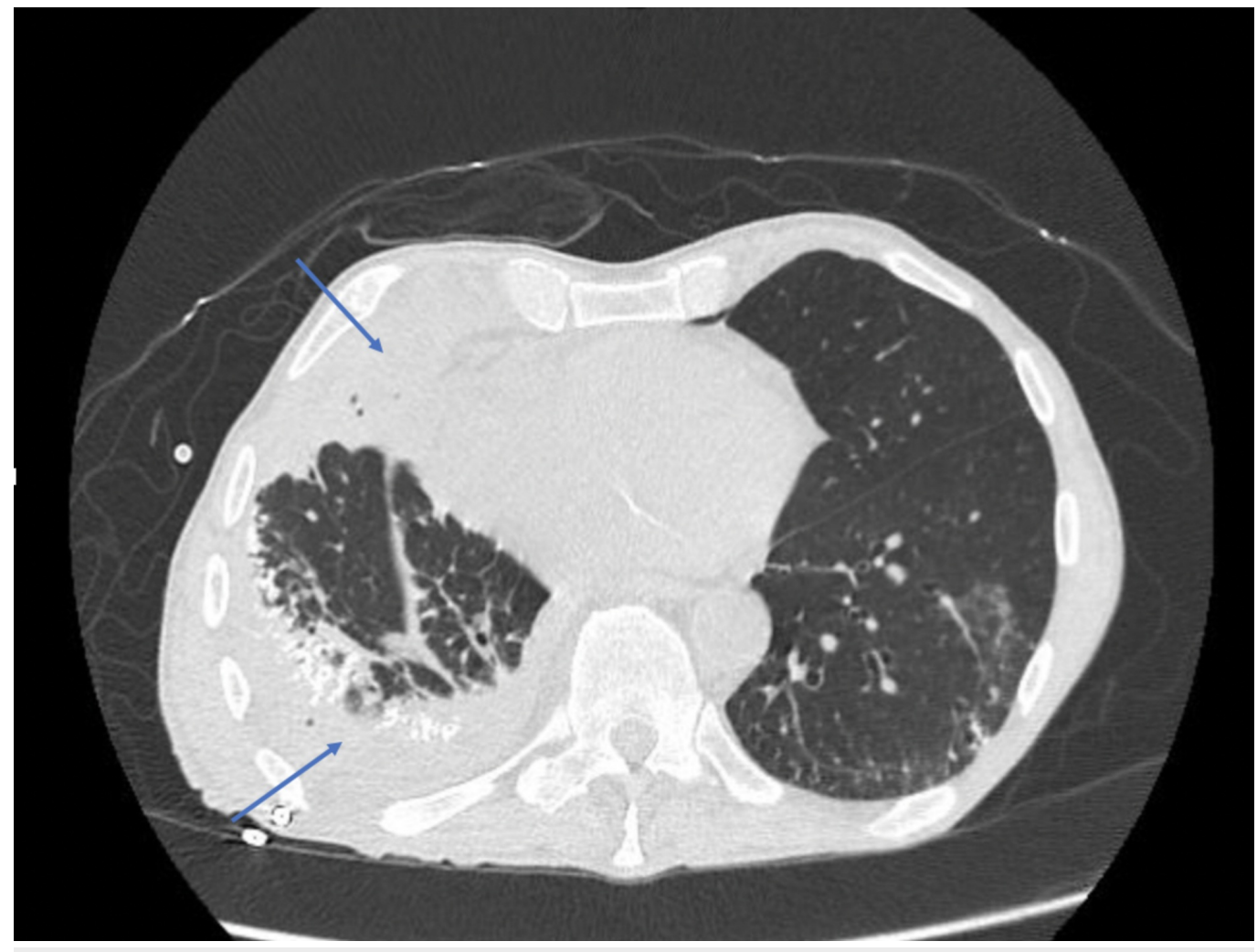

FIGURE 1: Loculated Pleural Effusion: Empyema

\section{Discussion}

Thoracic empyema is an infection of the pleural space that commonly occurs as a complication of pneumonia, malignancy, tuberculosis, or thoracic trauma. A pleural infection comprises empyema when presenting with frank pus in the pleura and complicated parapneumonic effusions in the absence of pus but with other signs of infection [2]. Early recognition and drainage are critical to the patient's survival and care. Many different types of bacteria may cause pneumonia leading to empyema, but the two most common are Streptococcus pneumoniae and Staphylococcus aureus. Our patient presented with empyema from a very unusual organism, S.gordonii.

S. gordonii is an anaerobic, gram-positive, non-motile coccus that is a member of the viridans group. S. gordonii is an inhabitant of the oral flora where it is the principal etiological agent of dental caries, causing the dissolution of tooth enamel by the acid end products resulting from carbohydrate metabolism [3]. This bacterium is capable of spreading to extraoral sites, causing systemic infection [1]. Viridans streptococci, such as S. gordonii, along with S. sanguinis and S. oralis, are commonly found in the blood cultures of patients with infective endocarditis [4]. S. gordonii is capable of colonizing platelet-fibrin thrombi formed on abnormal heart valves or the 
endocardium, thus it is frequently associated with causing subacute bacterial endocarditis [1]. However, there are only a few case reports of S. gordonii empyema reported in the literature.

The diagnosis of empyema is important for the rapid initiation of effective pleural drainage and appropriate antibiotic therapy. The optimal evaluation of empyema requires a contrastenhanced chest CT. The criteria for thoracentesis is a thickened parietal pleura on a contrastenhanced CT scan, a finding suggestive of empyema [5]. Ultrasonography of the pleural space allows for the characterization of pleural fluid collections with septations and loculations. The pleural fluid should be sent for a microbiologic analysis, cell count with differential, and chemistries.

Management and treatment options for thoracic empyema include systemic antibiotic therapy, adequate pleural fluid drainage, and obliteration of the empyema [6]. Tube thoracostomy, video-assisted thoracoscopic surgery (VATS), open decortication, and open thoracostomy are the drainage options for empyema. Adequate pleural fluid drainage is achieved when repeat imaging through a chest CT demonstrates the disappearance of any residual loculations [6].

\section{Conclusions}

S. gordonii is an anaerobic, gram-positive member of the viridans group Streptococci and is a natural inhabitant of the oral cavity. This report illustrates a rare case of thoracic empyema caused by S. gordonii. Our patient presented with a loculated effusion with the characteristics of empyema, which failed to resolve after antibiotic treatment, multiple drainage, and tPA administration. The patient was transferred to a more advanced center for VATS decortication.

\section{Additional Information \\ Disclosures}

Human subjects: Consent was obtained by all participants in this study. Conflicts of interest: In compliance with the ICMJE uniform disclosure form, all authors declare the following:

Payment/services info: All authors have declared that no financial support was received from any organization for the submitted work. Financial relationships: All authors have declared that they have no financial relationships at present or within the previous three years with any organizations that might have an interest in the submitted work. Other relationships: All authors have declared that there are no other relationships or activities that could appear to have influenced the submitted work.

\section{References}

1. Battista R, Raddi A, Labonia F, et al.: Subacute bacterial endocarditis (SBE) due to Streptococcus gordonii. Microbiologia Medica. 2009, 24:10.4081/mm.2009.2518

2. Khan J A, Lehtomäki AI, Toikkanen VJ, Ukkonen MT, Nevalainen RM, Laurikka JO: Long-term prognosis and causes of death after pleural infections. Scand J Surg. 2018, 107:145-151. 10.1177\%2F1457496917738868

3. Cvitkovitch DG, Li YH, Ellen RP: Quorum sensing and biofilm formation in Streptococcal infections. J Clin Invest. 2003, 112:1626-1632. 10.1172/JCI20430

4. Von Reyn CF, Levy BS, Arbeit RD, Friedland G, Crumpacker CS: Infective endocarditis: an analysis based on strict case definitions. Ann Intern Med. 1981, 94:505-518.

5. Heffner JE, Klein JS, Hampson C: Diagnostic utility and clinical application of imaging for pleural space infections. Chest. 2010, 137:467-479. 10.1378/chest.08-3002

6. Wozniak CJ, Paull DE, Moezzi JE, Scott RP, Anstadt MP, York VV, Little AG: Choice of first intervention is related to outcomes in the management of empyema. Ann Thorac Surg. 2009, 87:1525-1531. 10.1016/j.athoracsur.2009.01.028 